\title{
About Black Holes
}

\section{Sankar Palchoudhury}

101/673/A, College Para, P.O. Kharia, Ward No. 21, Dist. Jalpaiguri, Pin Code - 735101, West Bengal, India

sankarpalchoudhury@gmail.com

Received Feb 2021

Received in revised: Feb 2021

Published: March 2021

\begin{abstract}
ABSTRA CT
All kinds of waves occur for the disturbances in the quiet gravitational field. Different waves powered differently and propagated in the gravitational field. A black hole is the higher GFI (Gravitational Field Intensity) area. The rays do not possess, coming from a distant source when pass by the black holes, adequate strength to disturb in the higher GFI area of the black holes. Naturally, the rays take on a curve path as the provision in a circular area depends on the radius (distance), keeping distance according to the lower GFI area around the black holes' centre.
\end{abstract}

Keywords: Gravitational Field Intensity, Black Holes, curve path.

C2021 The Authors. Published by Fundamental Journals. This is an open access article under the CC BY-NC https://creativecommons.org/licenses/by-nc/4.0/

\section{INTRODUCTION}

A wave has two primary characters-one is the wavelength, and the other is amplitude. Both co-exist with each other. One's existence is not possible, except other(Palchoudhury, 2020b). We define a complete wavelength has two parts - one is a crest, and the other is a trough. A complete wave is a single frequency (Palchoudhury, 2020a). Palchoudhury wave equation is $F=K i A / \lambda$ and $P=F f$. Here $F$ is force of a unit wave, $k$ is constant of proportionality, $i$ is the gravitational field intensity of the local area, $\lambda$ is wavelength in SI unit $(m), A$ is wave amplitude in SI unit (m), $P$ is force of a wave per second and $f$ is frequency of wave per second. Gravitational field and gravitational fabric, as noted by Einstein, can describe as follows.
A gravitational field exists around a body. Gravitational fabric is the gravitational field spread all over the universe.

The gravitational fabric's strength is the gravitational field intensity that depends on its mass and distance from the body's centre. Before passing the rays by the side of a black hole from a distant source, rays have to pass through different lower gravitational field intensity area and loss power (Palchoudhury, 2020a).

And waves unable to make a disturbance in the higher gravitational field intensity area of black holes. The rays cannot pass $\mathrm{AB}$ in a straight line (Fig 1) and waves take a circular way to pass, what we may call a curve path, keeping an adequate distance from the centre of gravity according to GFI of the area where the wave cannot make disturbances in the higher GFI area. This curve path may help us assess the 
actual mass of Black holes. We may call the area of the curve path area as the event horizon (Fig 1). We can imagine a radius $r$ from the centre of gravity and treat the radius as a distance from the black holes' centre of gravity. Circumference $2 \pi r$ depends on radius. Every point of circumference indicates the distance from the center of black holes and the GFI's strength.
The circumference is circular. The curve path follows circumference for higher GFI of black holes and moves circularly. So, rays follow a curve path depending on GFI as the area marked by circumference. The curve path depends on the viewer's situation too.

Table 1: About Unit Wave

\begin{tabular}{l|ccccccc}
\hline Unit Wave & $\boldsymbol{k}$ & $\boldsymbol{i}$ & $\boldsymbol{\lambda}$ & $\boldsymbol{A}$ & $\boldsymbol{F}$ & $\boldsymbol{f}$ & Local area force at Earth (P) \\
\hline *Red & $1.9199 \mathrm{E}-34$ & 9.798 & $6.86 \mathrm{E}-07$ & $2.42 \mathrm{E}-07$ & $6.64 \mathrm{E}-34$ & $4.37 \mathrm{E}+14$ & $2.90 \mathrm{E}-19$ \\
Red & $1.9199 \mathrm{E}-34$ & 1 & $6.86 \mathrm{E}-07$ & $2.42 \mathrm{E}-07$ & $6.77 \mathrm{E}-35$ & $4.37 \mathrm{E}+14$ & $2.90 \mathrm{E}-19$ \\
\hline
\end{tabular}

* (Palchoudhury, 2020b)

Table 2: Various Waves and its local area force per second

\begin{tabular}{|c|c|c|c|c|c|}
\hline Various wave & Range & $\lambda$ & $\boldsymbol{A}$ & $f$ & Local area power $(P)$ at the Earth \\
\hline \multirow{2}{*}{ Red } & $B$ & $6.25 \mathrm{E}-07$ & $2.20 \mathrm{E}-07$ & $4.80 \mathrm{E}+14$ & $3.18 \mathrm{E}-19$ \\
\hline & $E$ & 7.40E-07 & $2.61 \mathrm{E}-07$ & $4.05 \mathrm{E}+14$ & $2.69 \mathrm{E}-19$ \\
\hline \multirow{2}{*}{ Orange } & $B$ & $5.90 \mathrm{E}-07$ & $2.08 \mathrm{E}-07$ & $5.08 \mathrm{E}+14$ & $3.37 \mathrm{E}-19$ \\
\hline & E & $6.25 \mathrm{E}-07$ & $2.20 \mathrm{E}-07$ & $4.80 \mathrm{E}+14$ & $3.18 \mathrm{E}-19$ \\
\hline \multirow{2}{*}{ Yellow } & $B$ & $5.65 \mathrm{E}-07$ & $1.99 \mathrm{E}-07$ & $5.31 \mathrm{E}+14$ & $3.52 \mathrm{E}-19$ \\
\hline & $E$ & $5.90 \mathrm{E}-07$ & $2.08 \mathrm{E}-07$ & $5.08 \mathrm{E}+14$ & $3.37 \mathrm{E}-19$ \\
\hline \multirow[b]{2}{*}{ Green } & $B$ & $5.00 \mathrm{E}-07$ & $1.76 \mathrm{E}-07$ & $6.00 \mathrm{E}+14$ & $3.98 \mathrm{E}-19$ \\
\hline & E & $5.65 \mathrm{E}-07$ & $1.99 \mathrm{E}-07$ & $5.31 \mathrm{E}+14$ & $3.52 \mathrm{E}-19$ \\
\hline \multirow[b]{2}{*}{ Cyan } & $B$ & $4.85 \mathrm{E}-07$ & $1.71 \mathrm{E}-07$ & $6.18 \mathrm{E}+14$ & $4.10 \mathrm{E}-19$ \\
\hline & $E$ & $5.00 \mathrm{E}-07$ & $1.76 \mathrm{E}-07$ & $6.00 \mathrm{E}+14$ & $3.98 \mathrm{E}-19$ \\
\hline \multirow{2}{*}{ Blue } & $B$ & $4.50 \mathrm{E}-07$ & $1.59 \mathrm{E}-07$ & $6.66 \mathrm{E}+14$ & $4.42 \mathrm{E}-19$ \\
\hline & $E$ & $4.85 \mathrm{E}-07$ & $1.71 \mathrm{E}-07$ & $6.18 \mathrm{E}+14$ & 4.10E-19 \\
\hline \multirow[b]{2}{*}{ Violet } & $B$ & $3.80 \mathrm{E}-07$ & $1.34 \mathrm{E}-07$ & $7.89 \mathrm{E}+14$ & $5.23 \mathrm{E}-19$ \\
\hline & $E$ & $4.50 \mathrm{E}-07$ & $1.59 \mathrm{E}-07$ & $6.66 \mathrm{E}+14$ & $4.42 \mathrm{E}-19$ \\
\hline \multirow{2}{*}{ Infrared } & $B$ & $7.50 \mathrm{E}-07$ & $2.64 \mathrm{E}-07$ & $4.00 \mathrm{E}+14$ & $2.65 \mathrm{E}-19$ \\
\hline & $E$ & $1.00 \mathrm{E}-03$ & $3.53 \mathrm{E}-04$ & $3.00 \mathrm{E}+11$ & $1.99 \mathrm{E}-22$ \\
\hline \multirow{2}{*}{ Band Wave } & $B$ & $1.26 \mathrm{E}-06$ & $4.44 \mathrm{E}-07$ & $2.38 \mathrm{E}+14$ & $1.58 \mathrm{E}-19$ \\
\hline & $E$ & $1.68 \mathrm{E}-06$ & $5.92 \mathrm{E}-07$ & $1.78 \mathrm{E}+14$ & $1.18 \mathrm{E}-19$ \\
\hline \multirow[b]{2}{*}{ Radio wave } & $B$ & $1.00 \mathrm{E}+00$ & $3.53 \mathrm{E}-01$ & $3.00 \mathrm{E}+08$ & $1.99 \mathrm{E}-25$ \\
\hline & $E$ & $1.00 \mathrm{E}+05$ & $3.53 \mathrm{E}+04$ & $3.00 \mathrm{E}+03$ & $1.99 \mathrm{E}-30$ \\
\hline \multirow{2}{*}{ Microwave } & $B$ & $1.00 \mathrm{E}-03$ & $3.53 \mathrm{E}-04$ & $3.00 \mathrm{E}+11$ & $1.99 \mathrm{E}-22$ \\
\hline & $E$ & $1.00 \mathrm{E}+00$ & 3.53E-01 & $3.00 \mathrm{E}+08$ & $1.99 \mathrm{E}-25$ \\
\hline \multirow{2}{*}{ Ultra-violate } & $B$ & $1.00 \mathrm{E}-08$ & $3.53 \mathrm{E}-09$ & $3.00 \mathrm{E}+16$ & $1.99 \mathrm{E}-17$ \\
\hline & $E$ & $4.00 \mathrm{E}-07$ & $1.41 \mathrm{E}-07$ & $7.49 \mathrm{E}+14$ & 4.97E-19 \\
\hline \multirow{2}{*}{ X-ray } & $B$ & $1.00 \mathrm{E}-11$ & $3.53 \mathrm{E}-12$ & $3.00 \mathrm{E}+19$ & $1.99 \mathrm{E}-14$ \\
\hline & $E$ & $1.00 \mathrm{E}-08$ & $3.53 \mathrm{E}-09$ & $3.00 \mathrm{E}+16$ & $1.99 \mathrm{E}-17$ \\
\hline \multirow{2}{*}{ Gamma Ray } & $B$ & $1.00 \mathrm{E}-18$ & $3.53 \mathrm{E}-19$ & $3.00 \mathrm{E}+26$ & $1.99 \mathrm{E}-07$ \\
\hline & $E$ & $1.00 \mathrm{E}-12$ & $3.53 \mathrm{E}-13$ & $3.00 \mathrm{E}+20$ & $1.99 \mathrm{E}-13$ \\
\hline \multirow{2}{*}{ Gravitational Wave } & $B$ & $1.00 \mathrm{E}+05$ & $3.53 \mathrm{E}+04$ & $3.00 \mathrm{E}+03$ & $1.99 \mathrm{E}-30$ \\
\hline & $E$ & $1.00 \mathrm{E}+06$ & $3.53 \mathrm{E}+05$ & $3.00 \mathrm{E}+02$ & $1.99 \mathrm{E}-31$ \\
\hline
\end{tabular}

$k=1.9199 \times 10^{-34}, i=1, F=6.77 \times 10^{-35}, B=$ Beginning of a range, $E=$ Ending of a range

Table 3: Cause of Curve path of waves in black holes

\begin{tabular}{l|ccccccc}
\hline Blackholes* & Mass $\left(M_{\odot}\right)$ & Distance $(m)$ & GFI at the distance & $\lambda$ & $A$ & $f$ & $\begin{array}{c}\text { Power }(\mathrm{P}) \text { require } \\
\text { to make disturbance }\end{array}$ \\
\hline SgrA & 4600000 & $8.00 \mathrm{E}+09$ & $9.11 \mathrm{E}+06$ & $1.00 \mathrm{E}-18$ & $3.53 \mathrm{E}-19$ & $3.00 \mathrm{E}+26$ & $1.85 \mathrm{E}-01$ \\
NGC-205 & 90000 & $6.00 \mathrm{E}+08$ & $3.17 \mathrm{E}+07$ & $1.00 \mathrm{E}-18$ & $3.53 \mathrm{E}-19$ & $3.00 \mathrm{E}+26$ & $6.43 \mathrm{E}-01$ \\
Messier-33 & 50000 & $5.00 \mathrm{E}+07$ & $2.54 \mathrm{E}+09$ & $1.00 \mathrm{E}-18$ & $3.53 \mathrm{E}-19$ & $3.00 \mathrm{E}+26$ & $5.15 \mathrm{E}+01$ \\
\hline
\end{tabular}

*(Sten.F.Odenwald, 2019)

Gravitational Constant $G=6.67 \times 10^{-11}$, Solar Mass $\left(M_{\odot} \approx 1.9 \times 10^{30}\right) / \mathrm{kg}$, Wave Constant $(k)=1.92 \times 10^{-34}$. GFI of Sgr A

$$
G F I=\frac{6.67 \times 10^{-11} \times 4.6 \times 10^{6} \times 1.9 \times 10^{30}}{\left(8 \times 10^{9}\right)^{2}}=9.11 \times 10^{6}
$$


As, for example, power of Gamma Ray at the earth GFI = $1.99 \times 10^{-7}$ to $1.99 \times 10^{-13}$ (Table 2) what is low to overcome strength of black holes at GFI (Table 3) and the waves take curve path choosing adequate low GFI area. (Sten.F.Odenwald, 2019)

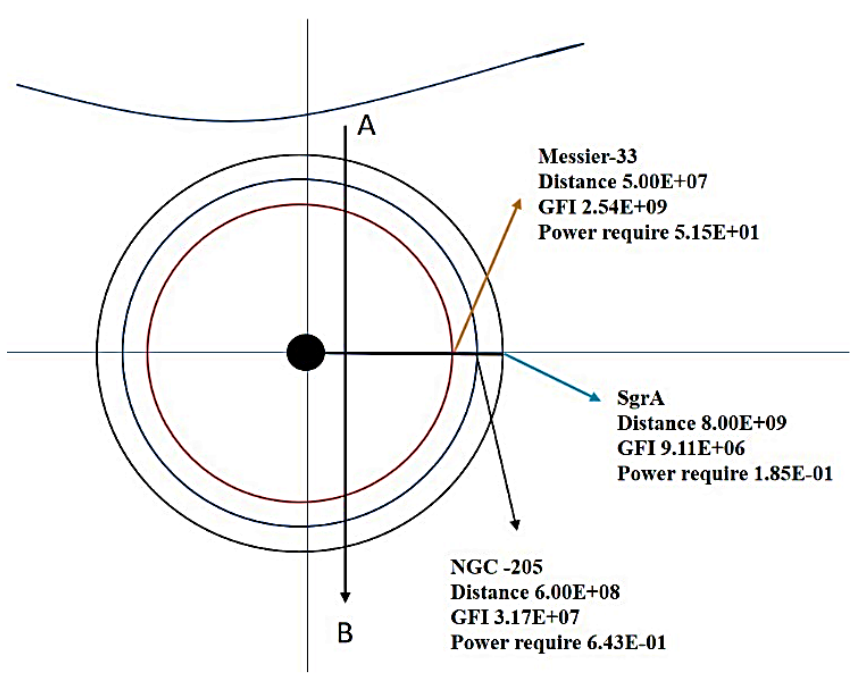

Figure 1: Source of various waves of distant stars

In general, waves rush with higher power from higher GFI area (like the sun) to lower GFI area (like earth) and loss some power (Palchoudhury, 2020a). On the other hand, waves rush with lower power from a lower GFI area (like earth) to a higher GFI area (like black holes). Waves have to face a barrier for lack of adequate power higher GFI to make disturbance and wavelength decrease gradually.

Once at a time, waves lose their existence and dissolve in the quiet gravitational field. Due to lack of adequate power in black holes, waves lose their existence and cannot enter the deep black holes. By naked eye, we see thousands and thousands of little stars in the night sky. All of those are not little ones. They are like the sun and more significant than the sun. Those generate various waves with reliable

\section{REFERENCES}

Palchoudhury, S. (2020a). Gravitational Field Intensity and Shifting of Waves: Physics-Gravitation. International Journal of Fundamental Physical Science, 10(4), 55-57. https://doi.org/10.14331/ijfps.2020.330142

Palchoudhury, S. (2020b). The Wave Nature Phenomena and the Gravitational Field: Physics. International Journal of power and spreads in the universe. However, do not reach the earth as strong as rays from the sun. The cause is this that ray of distant stars has to cross the longdistance through the low GFI area and lose its power. We find soft light from the distant stars. Waves coming from other sources continually shift according to the GFI of the local area and categories according to the range of wavelength. (Table 2). Waves of the low GFI area with the lower power rush to higher GFI area and face to overcome the higher GFI barrier, but the lack of adequate power waves face a compression in the higher GFI area and wavelength decrease. We can define the according to the wavelength range (Table 2) the wave. Again, the high GFI area waves with the higher power rush to lower GFI area wavelength increase. We define, according to the wavelength range (Table 2), the wave. Always, waves travel from a different source in a shifting manner accordingly.

The wavelength of a wave decreases when it transfers a lower GFI area to a higher GFI area. A wave wavelength increases when it transfers from a higher GFI area to a lower GFI area. The waves run in the gravitational field on compression and expansion according to GFI and its strength.

\section{CONCLUSION}

All kinds of wave occur for the disturbance in the quiet gravitational field. The rays do not possess, coming from the distant source when passing by the black holes, adequate strength to disturb the black holes' higher GFI area. Naturally, it follows in a curve path in a circular way, keeping distance according to the lower GFI area around the centre of black holes.

\section{ACKNOWLEDGEMENT}

I, the author, express sincerely at this moment gratefulness to the editor-in-chief, reviewers, and editorial staff of the International Journal of Fundamental Physical Sciences (IJFPS) for their valuable suggestion towards the improvement of the manuscript.

Fundamental Physical Science, 10(2), 12-15. https://doi.org/10.14331/ijfps.2020.330136

Sten.F.Odenwald. (2019). Black Hole Math NASA (National Aeronautics and Space Administration). NASA. http://spacemath.gsfc.nasa.gov 